\title{
Primary care in Caribbean Small Island Developing States
}

\author{
How do organisation of primary care systems and health relate?
}

J.D. Kranenburg ${ }^{1,2 *}$, and D.R. Essink ${ }^{1}$

${ }^{1}$ Athena Institute Amsterdam, Amsterdam, The Netherlands

${ }^{2}$ Global Health Next Generation Network, Barcelona, Spain

*Corresponding author's e-mail address: jdkranenburg@gmail.com

Published online: 20 May 2015 (version 1)

Cite as: J.D. Kranenburg and D.R. Essink ScienceOpen Research 2015 (DOI: 10.14293/S2199-1006.1.SOR-MED.AVUQD7.v1)

Reviewing status: Please note that this article is under continuous review. For the current reviewing status and the latest referee's comments please click here or scan the QR code at the end of this article.

Primary discipline: Public health

Secondary discipline: General medicine, Health \& Social care

Keywords: Primary care, Caribbean region, Health care systems, Small island developing states, Non-communicable disease

\begin{abstract}
Caribbean Small Island Developing States (SIDS) made good process on improving the health of their populations; but concerns exist when it comes to meeting changing health needs. Due to remoteness and limited resources it is difficult to respond to high rates of non-communicable diseases (NCDs). Furthermore, little is known about how primary care (PC) is organised and how this responds to current health issues. This study focused on gaining insights in the organisation of PC of Caribbean SIDS based on currently available literature. This literature review was an explorative multiple case study, where structure of PC and health status of 16 Caribbean SIDS were reviewed using available scientific and grey literature between the years 1997 and 2014. Thirty documents were used to analyse 20 indicators for the dimensions "Structure of Primary Care" and "Health Status". Results were mapped in order to identify if there is a possible relation between structures of PC to the health of the populations. When reviewing the structure of $\mathrm{PC}$, the majority of information was available for "Economic conditions of PC" (78\%) and the least information was available for "Governance of PC" (40\%). With regards to health status, all islands show improvements on "Life expectancy at birth" since 2007. In contrast, on average, the mortality due to NCDs did not improve. Saint Lucia performs best on "Structure of PC". The British Virgin Islands have the best health status. When both dimensions were analysed, Saint Lucia performs best. There is still little known on the responsiveness of PC of Caribbean SIDS to NCDs. There is a need for elaborate research on: (1) If and how the functioning of these health systems relate to the health status; (2) What islands can learn from an analysis over time and what they can learn from cross-island analysis; and (3) Filling the gaps of knowledge which currently exist within this field of research.
\end{abstract}

\section{INTRODUCTION}

Small Island Developing States (SIDS) made good progress in achieving the Millennium Development Goals (MDGs). However, concerns exist regarding the health of the population of these islands, in particular, the Caribbean SIDS, who have transitioned from high communicable diseases region to an increasing prevalence of non-communicable diseases (NCDs). The prevalence of obesity in the Caribbean is amongst the highest of the world [1, 2]. The five-year evaluation of the Mauritius Strategy of Implementation (MSI+5) for the Caribbean showed that health standards have worsened for NCDs. Patients complain about the deterioration of quality of health services and there is an inability of health administrations to respond to changing needs of patients $[1,2]$. In addition, health systems of SIDS face the persistent challenge of limited capacity and skills of health care workers due to emigration, the remoteness, the size and the economic opportunities [1-6].

Health is not solely evaluated within in the MSI and MSI+5. Health system performance and health are assessed and monitored by the Pan American Health Organization (PAHO). PAHO attempts to regionally strengthen health systems of Latin American Countries by assessing Essential Public Health functions and reporting health system performance with the publications of "Health in the Americas" reports [2, 7, 8]. Even though health care systems are assessed regularly, little scientific research was done on the factual organisation and its relation to the health. It is of importance to find out to what extent reforms need to be done in the organisation to meet the "new" needs of the populations. When it comes to the response of prevention and treatment of NCDs, primary care (PC) is the first point of contact. Therefore it plays a pivotal role in the health care system [9-11]. For SIDS a good and efficient organisation of PC is even more so important due to the remoteness and limited resources $[1,12]$. 
Little is known about how PC is organised and how this responds to current health issues. An assessment of the structure PC could therefore give significant information about where improvements can be done to increase the responsiveness of the health systems. In addition, crossisland comparisons can give an opportunity to learn from other islands in a similar context. The aim of this study was to gain insight in the organisation of primary health systems in relation to health status of SIDS in the Caribbean. In addition, this study attempts to create an overview on current performance of the systems in this region. Furthermore, we tried to identify gaps in available literature in order to make recommendations for future research and actions to innovate the health systems of Caribbean SIDS.

\section{FRAMEWORK}

Within the health care system, PC is seen as an integral part. PC is defined as following in the Alma-Ata Declaration: "Primary health care is essential health care based on practical, scientifically sound and socially acceptable methods and technology made universally accessible to individuals and families in the community through their full participation and at a cost that the community and country can afford to maintain at every stage of their development in the spirit of self-reliance and self-determination" [13].

The framework used for this study was based on the "Primary Care System Framework" by Kringos, which is a framework developed to assess the performance of PC systems of European countries. Kringos [14] identifies three dimensions in PC, namely: PC structure, PC process and PC outcomes. Each dimension has several sub-dimensions which play an important role within PC. Within these sub-dimensions, several indicators were identified in order to assess PC systems.

This study solely focused the organisation of the health care system. Furthermore, we chose to change the dimension of PC outcomes into "Health status" to get insight in this dimension and into what extent the organisational structure of PC relates to the health status. Moreover, good health of the population is eventually the final aim of a health system WHO [15]. Figure 1 illustrates which dimensions and sub-dimensions were used to structure this study.

\section{DEFINITION OF CONCEPTS}

The structure of primary care includes legislation, policies, the remuneration system and the factual organisation of PC. This dimension was divided into three sub-dimensions, namely: economic conditions of PC, governance of PC and PC workforce. For each these, a couple of indicators were used to assess the structure of PC [14].

The primary care workforce comprises the availability of PC professionals and PC facilities for the population. For this study PC workforce was divided into three important aspects which give information on how the PC workforce is

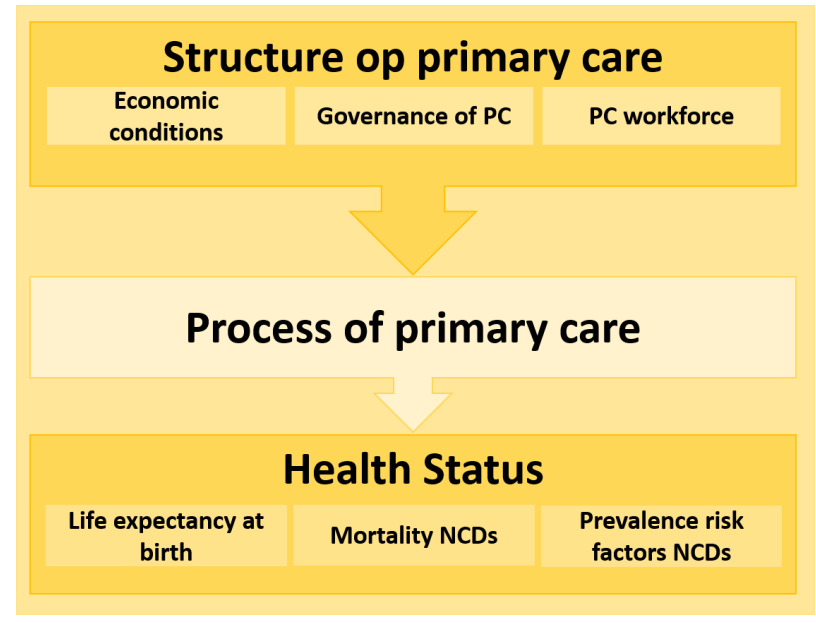

Figure 1. Dimensions and sub-dimensions used during this literature review.

organised. These three aspects are: coverage of PC through health facilities, number of general practitioners and allied health professional and number of educational facilities for health professionals [14].

Health status of a population can be measured by using indicators such as mortality indicators, life expectancy at birth, disability-affected life years and prevalence indicators. These indicators can give insight how healthy a population is. In order to get insight in the health status of the population in terms of NCDs, health status indicators "life expectancy at birth", "mortality due to NCDs" and "prevalence of risk factors of NCDs" were used. The following leading NCDs were taken into account during this study: heart diseases, cerebrovascular diseases and diabetes $[7,8]$.

\section{METHODS}

This study was an explorative multiple case study. Available literature was reviewed to gain insight in the organisational performance of PC systems in relation to the health status of the populations. Literature was systematically searched between January 2014 and April 2014. Both scientific and grey literature were included. The following electronic databases were searched for scientific literature: PubMed, Science Direct and LILACS. Additionally, a search for grey literature was done on the website of the World Health organization (WHO), United Nations (UN), Caribbean Community Secretariat (CARICOM), the Small Island Developing States Network (SIDSnet), Alliance of Small Island States, PAHO and the Caribbean Public Health Agency. This was done to retrieve additional information that could not be found in scientific literature (e.g. governmental/regional policies). The search was limited to documents written in English and Dutch, published between the years 1997 and 2014. 
Table 1. Included islands.

\begin{tabular}{lrr}
\hline Included Caribbean SIDS & Population & \multicolumn{1}{c}{$\mathbf{K m}^{\mathbf{2}}$} \\
\hline Anguilla & 11,430 & 91 \\
Antigua and Barbuda & 76,886 & 442 \\
Aruba & 101,484 & 180 \\
Bahamas & 353,658 & 13,943 \\
Barbados & 250,010 & 430 \\
British Virgin Islands & 20,647 & 151 \\
Dominica & 71,293 & 751 \\
(former) Netherlands Antilles & 197,600 & 800 \\
Grenada & 102,632 & 344 \\
Montserrat & 4,491 & 102 \\
Puerto Rico & 3725,789 & 8,870 \\
Saint Kitts and Nevis & 45,841 & 261 \\
Saint Lucia & 173,720 & 539 \\
Saint Vincent and the Grenadines & 109,022 & 389 \\
Trinidad and Tobago & 1324,699 & 5,130 \\
Jamaica & 2607,632 & 10,991 \\
\hline Sourc: United Nations &
\end{tabular}

Source: United Nations Demographic Yearbook, 2012.

\section{In- and exclusion criteria}

Because this study focused on Small Island states, with an emphasis on small islands, the following inclusion criteria were used. Countries should be listed as a Caribbean SIDS country, be a small island as defined by Demas [16] (population of maximum 5 million people, an area of maximum $30,000 \mathrm{~km}^{2}$ and all borders should be coastlines). Islands can be a single island, a small group of islands or a large group of islands (archipelago) running under the same government. Caribbean SIDS not fulfilling the inclusion criteria were excluded from this study. Table 1 shows an overview of islands that were included in this the study.

\section{Data collection}

Search strategies were tested for Subject Headings MeSH terms relating to PC systems, Caribbean SIDS and NCDs. These MeSH terms were searched in titles and abstracts of studies. The search strategy was devised for use in PubMed and subsequently adapted for other databases and websites. For grey literature, websites were examined for reports and files which gave information on PC, the health system or the health status of populations of Caribbean SIDS.

A three-phase screening was done to assess usability before analyses. During the first screening, titles and abstracts were evaluated, to assess if the articles were fitting the aim of the research. Subsequently, scanning through the remaining, the full text documents were assessed for inclusion. Finally, after articles were fully read, they were in- or excluded based on the information that could be retrieved for indicators used during the analyses. For available grey literature such as reports, a similar screening process was done. Furthermore, statistical data retrieved on websites were assessed by the year it was published and the way it was collected or calculated. Table 2 illustrates how the process of selection was done.
Table 2. Document selection.

\begin{tabular}{lcc}
\hline $\begin{array}{l}\text { Search engine for } \\
\text { scientific literature }\end{array}$ & Articles & Articles analysed \\
\hline PUBMED & 382 & 4 \\
Science Direct & 40 & 1 \\
LILACS & 263 & 6 \\
\hline Website & Documents found & Documents analysed \\
\hline PAHO & 23 & 19 \\
World Bank & 1 & 0 \\
Nivel & 1 & 0 \\
\hline
\end{tabular}

\section{Analyses}

A total of 20 indicators were identified to assess the dimensions of PC structure and health status. A total of 12 PC structure indicator were used based on structure indicators described by Kringos [14] in the Primary Care Activity Monitor study [14]. A total of eight indicators were used to analyse the health status of the populations. These were focused on mortality and prevalence of NCDs. For these indicators most common NCDs in the Caribbean were chosen, namely, heart disease, cerebrovascular diseases and diabetes [8].

Results of reviewed literature were put into a matrix in order to get insight which indicators were retrieved. If $<33.33 \%$ information was retrieved for an indicator, it was excluded from further analyses to avoid a negative influence on the outcome of the indicator and possibly for the whole subdimension. Four indicators were excluded from further analyses based on these criterion. Moreover, if $<33.33 \%$ of indicators were found for an island, similarly to the indicators, the island was excluded from further analyses. The (former) Netherlands Antilles were excluded from further analyses based on this criterion.

In order to give insight into the performance of PC Structure indicators were scored. A simple scoring system was developed based on past studies. An average of scores was calculated per sub-dimension. Subsequently, an overall average was calculated for the whole dimension. In the process of calculating, the indicators and sub-dimensions were weighed equally. A high average indicates good structure in PC, whereas a low number indicates a bad structure in PC.

The dimension "Health status" indicators were ranked backwards per indicator. For example, the lowest life expectancy at birth was ranked as "1" and the second lowest was ranked "2", etcetera. This was done for all health status indicators. An average of health status was calculated with even weighing of the sub-dimensions of health status. Similarly to "the process of primary care", a high average means that the health status of the island indicates good health and a low number indicates that the health status is bad. Finally, the scores of the PC structure and health status were ranked and compared with one another to get information on if and how the "structure of 
primary care" influences the health status of the population of the islands.

During the process of analyses, large amounts of gaps were identified in the data. In the sub-dimensions of structure of PC an indicator with no data was scored " 0 ". In the dimension of health status missing data were ranked "1". This way of scoring could have led to an over- or underestimation of the different sub-dimensions with a lot of missing data. In order to give a more accurate presentation of reality, averages of the dimensions were corrected for missing data by taking the percentages of missing data into account. Adjusted averages were compared with the raw data averages to determine if there was an over or underestimation of data.

\section{RESULTS}

\section{Data representation}

In total 30 documents were used for analyses, of which 11 scientific articles and 19 grey literature documents. These analysed documents included information covering 58\% of the indicators. The majority of information was covered for the sub-dimension "Economic Conditions" (78\%). Within this sub-dimension, the majority of retrieved information was on the indicator "total health expenditure as \% of GDP (EC01.2)". In contrast, there were little data on the sub-dimension "Governance of Primary Health Care" (40\%). Within this subdimension, the smallest amount data were available on the indicators "Policy on distribution of human resources (GOV1.2)" (17\%) and "Stakeholders/community involvement on Policy development (GOV1.4)" (28\%). Therefore, these indicators were not used for further analyses. Furthermore, even though the indicators of dimension "Health status" covered $63 \%$, the results show that there was little information on two indicators, namely: "Prevalence Cerebro-vascular accidents" (6\%) and "Prevalence Heart Disease" (6\%). Similarly to the indicators of PC structure, these indicators were not taken into account during further analyses.

When considering the amount of information was available for different islands, it appeared that literature used for this study covered between $25 \%$ and $85 \%$ of the possible information. Furthermore, literature only gave information about $25 \%$ of the indicators for the (former) Netherlands Antilles, which indicates a knowledge/data gap for these islands. The (former) Netherlands Antilles were therefore excluded from further analyses. The majority of documentation was available on Trinidad and Tobago. Information about these islands was included in five articles and four grey literature documents $[7,8,17-24]$.

\section{PC structure}

When it comes to economic conditions of the PC, expenditures on health as \% of GDP ranged from 3.5\% in Saint Vincent and the Grenadines to $16.8 \%$ in Montserrat. Of these health expenditures, islands spent between $6 \%$ and $38 \%$ on PC. Antigua and Barbuda was ranked first when it comes to economic conditions. It scores high on the indicators "expenditure on health as a \% of GDP" and "expenditure on primary health care as \% of the total health budget". Antigua and Barbuda spent about $7 \%$ of their GDP on heath and of this budget they spent about $38 \%$ on PC. Of all the islands they spend the most on PC. Anguilla was ranked lowest when it comes to economic conditions. There was no information retrieved on whether or not they have a separate budget for PC. Furthermore, the funding of their health system is dependent on external funders. There was no information on which other possible mechanisms they use to fund their health system $[7,8]$.

The majority of islands score low on the indicator "Type of funding health systems". It appears that all islands are to some extent dependent of external funding to be able to pay for their health system. For this indicator Antigua and Barbuda and the British Virgin Islands score best, due to the fact that literature stated that the government is the main financer for health care. For the indicator "total health expenditure as a \% of GDP" the average expenditure on health care was about $8 \%$. The islands that spent most of their total health care budget were Montserrat and Puerto Rico with an expenditure of $16.80 \%$ and $16.40 \%$, respectively. Trinidad and Tobago score low because they only spent $3.5 \%$ of their GDP on health. Solely for Dominica, no information could be retrieved on the total health budget. For the islands Anguilla, Aruba, Bahamas, Montserrat and Puerto Rico, there was no information retrieved on the indicator "Expenditure of primary care as a $\%$ of total health expenditure". It is unknown if they have a budget and how high this possible budget for PC is, therefore they were scored " 0 "in this category [7, 8, 17, 19-21, 24-28].

\section{Governance of PC}

In the sub-dimension "Governance of PC" there were many gaps in reviewed documents. The range of data representation ranged from $44.44 \%$ to $50 \%$. For the indicator "PC goals" the lowest scores were given to Antigua and Barbuda, Aruba, Bahamas, Barbados, Dominica and Puerto Rico. The documentation on these islands did not contain information on whether or not their government defined PC goals. For Saint Lucia and Anguilla current documentation stated that these islands are still working on the development of a health care strategy/policy or they have the intention to do this in the near future. This indicates that a current strategy does not yet exist. Other islands scored highest on this indicator, because they had clear visions or goals for PC. For example Monserrat stated that they wanted a "strengthened district level delivery of health services with emphasis on primary care" in their sustainable development plan 2008-2011 [7, 8, 17, 18, 24, 27, 28, 29-39].

For the indicator "PC within the ministry of health" the islands Anguilla, Bahamas, Barbados, Montserrat and the British Virgin Islands in one way or another had a team/department within their ministry of health which works specifically for PC. 
This could be in the form of a separate department for PC which is the case in Anguilla or one person (a chief medical officer) that is responsible for the directing and managing of PC services like in Montserrat. Saint Kitts and Nevis and Saint Lucia do not appear to have a separate department focussing on PC and were therefore scored lowest. In multiple islands the focus of governance of PC activities and initiatives is increasingly on NCDs. Multiple states did already implemented regional strategies such as the Port-of-Spain declaration $[29,40]$. In addition, islands implement local strategies, start local initiatives and develop policies on NCD prevention and reduction.

\section{Workforce PC}

Most islands have a public health-based health system. Usually islands are partitioned in different districts which have their own health centres and hospitals. Some islands such as Antigua and Barbuda also make use of satellite clinics. PC health centres (sometimes also described as community health centres) offer services to an average of 5100 people. They provide main services such as: maternal and child health services including deliveries and immunisation, medical care, dental services, cancer screening, diabetic and hypertensive clinics, social mobilisation, health education, home visits and environmental health monitoring. Examples the type of disciplines working at these health centres are general practitioners, public health professionals, environmental health professionals, nurses, midwives, pharmacists and dentists. The occupation disciplines in health centres differ per island $[7,8,18,23,27,28,32-39,41,42]$.
Multiple documents stated that there are little possibilities to educate health personnel. Training in Medicine can solely be done on the islands of Saint Kitts and Nevis and Barbados. In Montserrat, Dominica, Saint Lucia, Saint Vincent and the Grenadines and Trinidad and Tobago, training of allied health care professions such as nursing and midwifery is possible. For other islands, health professionals are sometimes trained regionally, but to large extent students travel to the USA or to Europe to get their education as a health professional $[7,8,18$, 23, 27, 28, 32-39, 41, 42].

Results show that after scoring of the indicators of the "Structure of PC", Saint Lucia scored highest on structure; Barbados, Saint Kitts and Nevis shared second place. Within the sub-dimension "Economic conditions" Antigua and Barbuda scored highest followed by the British Virgin Islands. Furthermore, Saint Kitts and Nevis appeared to have best governance in PC. Finally, Saint Lucia and Dominica Ranked best within the sub-dimension "Workforce of PC". Figure 2 illustrates the scoring of the different sub-dimensions per island and how islands relate to each other.

\section{Health status}

For the indicators of health status, the Core Health Indicators were used. In addition, information from articles and grey literature documents were used if data were missing for indicators. The data used for this study were collected between 2000 and 2013 by PAHO [43]. When reviewing the health status of the populations of the islands, literature indicates that most islands have undergone an epidemiological transition from high prevalence of communicable diseases to NCDs. Literature stated that most countries have progressed a

\section{Scores sub-dimensions PC structure}

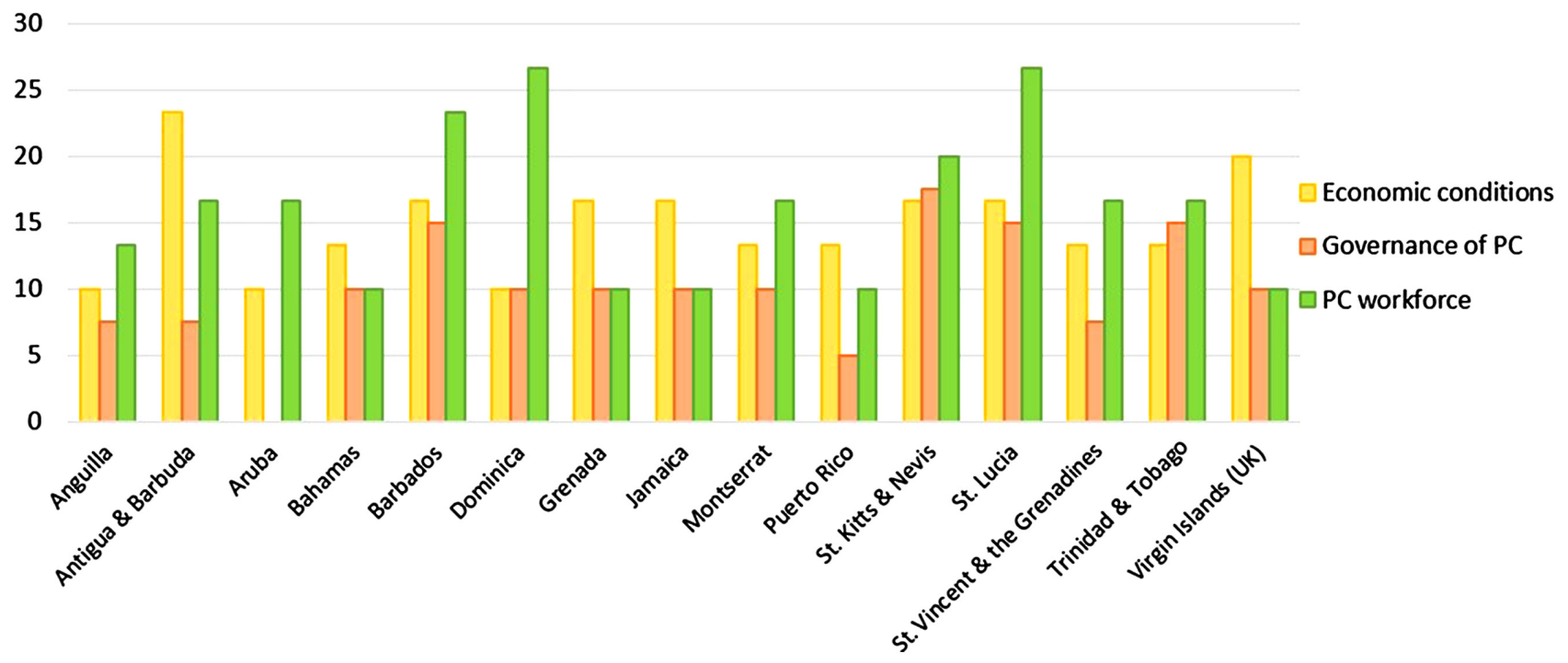

Figure 2. Scores on sub-dimensions of the structure of PC. 


\section{Scores sub-dimensions of Health Status}

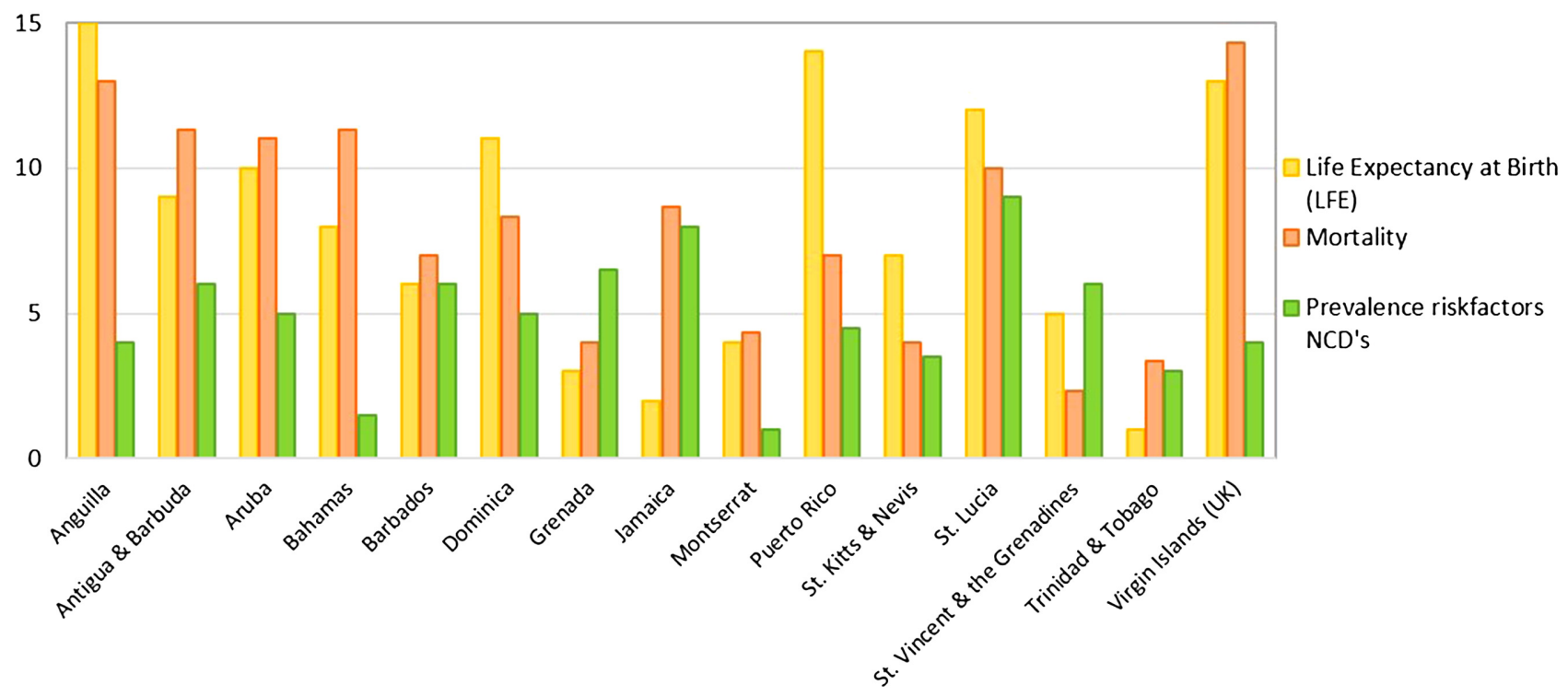

Figure 3. Average scores sub-dimension of health status.

lot when it comes to the populations' life expectancy $[7,8]$. For example life expectancy at birth increased from 76.6 in 2000 to 81.1 in 2013 for the population of Anguilla. Contrary to life expectancy at birth, mortality rates of NCDs do not seem to decrease for every island over the years [43].

Mortality due to heart disease, cerebrovascular disease and diabetes are usually within the top five causes of mortality of Caribbean SIDS [7, 8]. The mortality rate due to heart disease in Saint Vincent and the Grenadines went up to 110.7 per 100,000 population in 2011. Montserrat decreased its levels of mortality due to heart disease from 132.5 per 100,000 in 2005 to 77.8 in 2011. Moreover, little data are known on the mortality rates from heart disease over the years for Jamaica. A striking fact on mortality rate from heart disease is that numbers can fluctuate significantly between years. For example in Montserrat, the mortality rate raised from 66.5 per 100,000 pop to 196.9 in 2008 [43].

Saint Kitts and Nevis (34.5\%), Puerto Rico (34\%) and Barbados (27\%) have the highest prevalence of hypertension, while Antigua and Barbuda has the lowest prevalence of diabetes (7.0\%) [44]. The prevalence of diabetes on Caribbean SIDS is lower and ranged from $8.2 \%$ in Saint Lucia to $14.2 \%$ in the Bahamas [7, 8, 24].

Figure 3 illustrates the average ranking per sub-dimension. The results show that Anguilla has the highest life expectancy at birth and Trinidad and Tobago the lowest. The Virgin Islands have the lowest mortality rate, therefore they score best on mortality. In contrast, Saint Vincent and the Grenadines score lowest. Saint Lucia has the lowest prevalence of risk factors for NCDs, whereas Montserrat scores low to its high prevalence of risk factors.

\section{PC structure in relation to health status}

Figure 4 shows the average adjusted ranks of indicators of the dimensions "Structure of PC" and the "Health Status". Saint Lucia scores the highest when it comes to the structure of PC. In currently reviewed literature Puerto Rico scores lowest for the indicators of the structure of PC. Moreover, Saint Lucia seems to be having the best overall health status in comparison with the other islands, while Montserrat has the worst health status. The figure illustrates that some islands score high on the structure of PC but have score low on health status and vice versa; for example, Trinidad and Tobago scores relatively high on the structure of PC while it scores low on health status. While in contrast Aruba scores higher when it comes to health status and lower when it comes to the structure of their PC. In order to get an insight on whether there is a relation between "Structure of PC" and "Health Status", results were plotted in a scatterplot visualised in Figure 5. In this figure the size of the islands represents the circle size. The figure implies that there does not seem to be a relation between how PC is organised and the health status of the population. Furthermore, the size of the population does not seem to influence either of the dimensions

\section{DISCUSSION}

Results show that efforts have been made to give more insight into the organisation of the health systems of the Caribbean SIDS. Both governments as international institutions such as PAHO have been working on this in the past decades $[7,8]$. The majority information covered the sub-dimension "Economic conditions of Primary Care". The indicators used for this sub-dimension such as total health expenditure as a \% of GDP are commonly used indicators comparative health system 


\section{Adjusted scores PC structure and Health status of Caribbean SIDS}

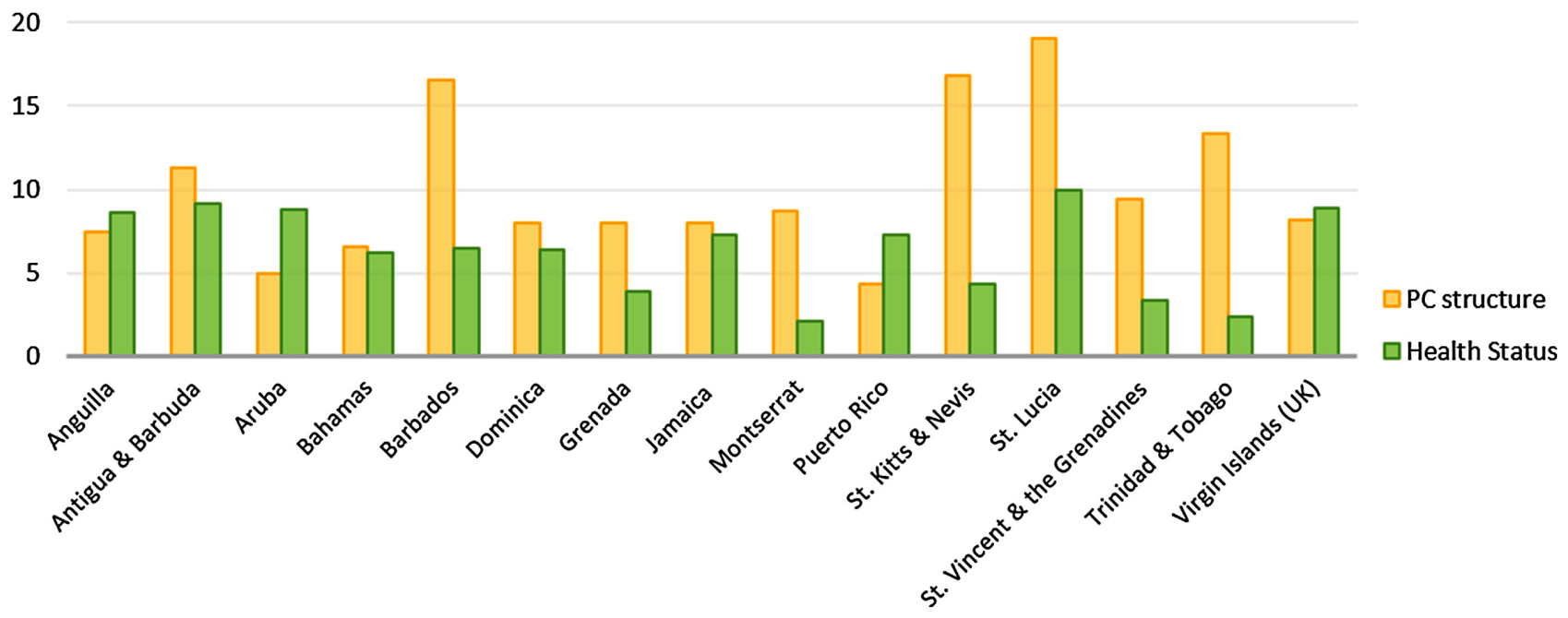

Figure 4. Scores of health status and PC structure.

studies [14, 45]. The "Health at a Glance" report by OECD [45] states that health spending of OECD countries accounts for 9.3\% of GDP. For the Caribbean SIDS this was about 8\%. Caribbean islands invest less in health care than countries that already have properly functioning health systems. According to Starfield and Macinko [46], poor financial investment is one of the weaknesses to delivery of PC. Furthermore, PAHO and CARICOM [2] state in their report that it is critical for Caribbean SIDS to allocate more of the national health budget to health. In current known comparisons it appears that there is still room to make greater use of taxes and social security contributions to meet the financing needs of the sector [2].

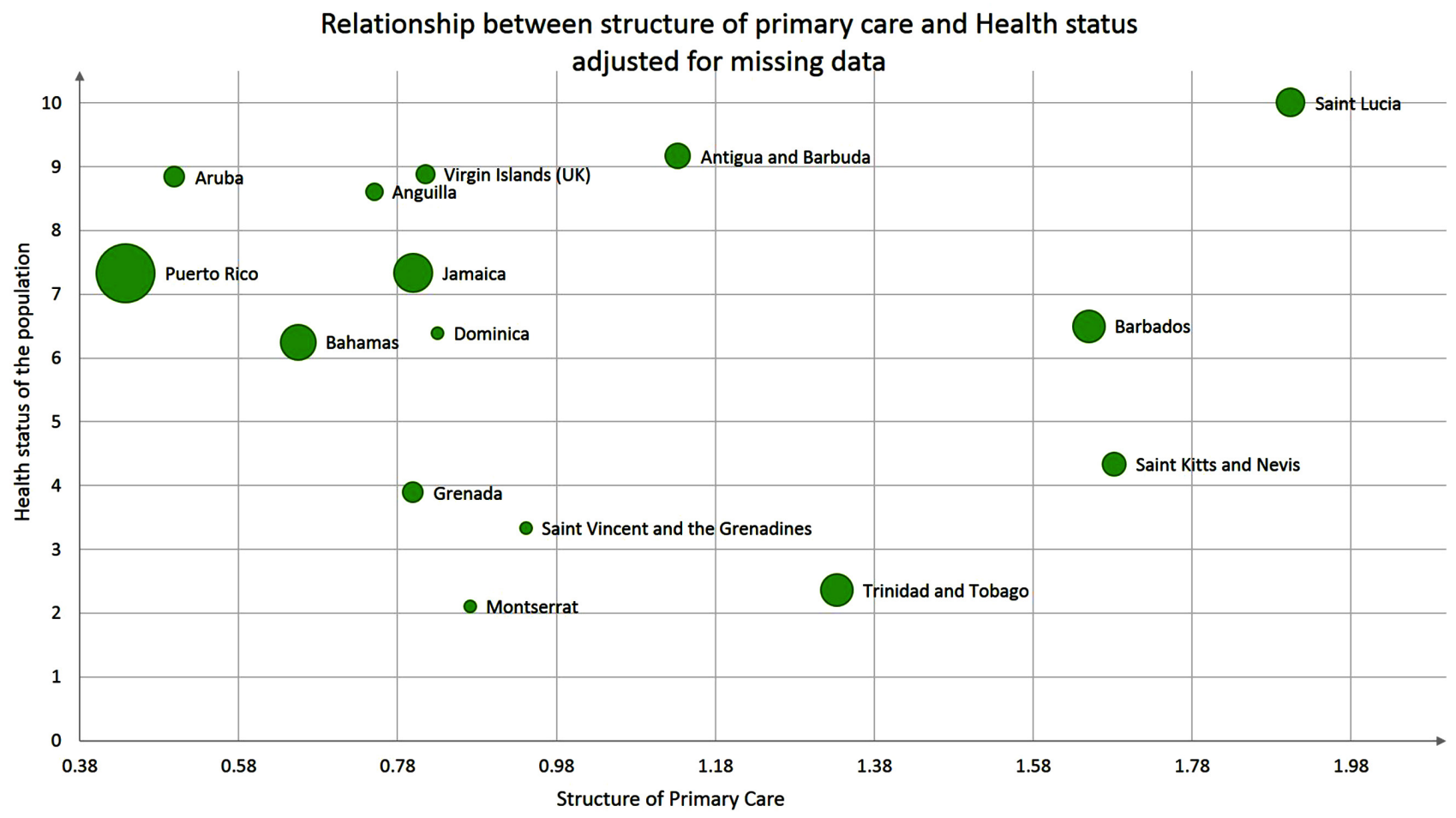

Figure 5. Relationship between structure of PC and health status. 
This evidence suggests that islands need to invest more into their health budget if they want to have a more sustainable health system [10, 47]. PAHO and CARICOM [2] specifically suggest that Caribbean SIDS should aim at a health expenditure of at least $6 \%$ of GDP and should put the emphasis for additional funding on the promotion of health and the prevention on NCDs [2].

Moreover, the importance of how allocations are done with the islands' budget is vital for a sustainable PC system. Filmer, Hammer, and Pritchett [48] state that low-income countries benefit from spending on PC rather than investing in hospital care. Moreover, the general agreement exists that investing on PC improves equity in health and is also associated with lower mortality and morbidity of the population [49-51]. Therefore, it is of importance to have insights in these budgets when it comes to the Caribbean SIDS. Little information was retrieved on the indicator "Expenditure on PC". An explanation for this can be that islands mostly have public health-based health system and therefore have a budget for public health services instead of solely PC. The ranges of health expenditure in PC varied from $3.5 \%$ to $38 \%$, with an average of about $21 \%$.

Little information was retrieved for the sub-dimension of "Governance of Primary Care". Even though there is a large amount of national and international initiatives to improve the health of the population with regard to NCDs, little information was available on how stakeholders are involved in the developments and policy formulations of the PC. Furthermore, there was very little information on the availability of policies to distribute human resources, while human resources are considered to be a chronic issue on the islands [2]. Previous research has concluded that stakeholder involvement in these processes is vital for getting ownership and the motivation for the reforms done in the health system. Furthermore, policies on the distribution of human resources in health are important for to tackle the problem of lack of health professionals $[10,47]$. Because so little is known about this sub-dimension in currently available literature, it is of great importance that islands get more insight within this sub-dimension.

In the sub-dimension of "Workforce of PC", one of the main problems the islands are facing is the inability to fulfil the needed health professionals. While different country analysis confirmed that an adequate supply of PC personnel has a positive influence on all-cause mortalities, the "brain drain" is a problem $[2,10,14]$. The "brain drain" phenomenon is a wellknown problem in LMICs, but this complex issue does not appear to have a standardised solution [52]. Moreover, islands also face the issue of not being able to provide the proper education of health professionals on the islands. PAHO and CARICOM [2] indicate that islands are already using a managed migration strategy to increase the human resources in health care, but still great shortages exist [2].

Results show that life expectancy is relatively low for some islands (e.g. Trinidad and Tobago) and mortality rates of NCDs are high (e.g. Trinidad and Tobago and Montserrat).
Furthermore, what is noticeable is that sometimes mortality rates can fluctuate extremely within a year of difference (e.g. Montserrat). Indicators used for health status were retrieved from Core Health Indicators, which are estimates calculated on the bases of deaths registered in national vital registration systems of islands [53]. The quality of the indicators is therefore dependent on the registration systems and the reporting of the islands. This could have influenced the results negatively, such as for example for Jamaica. For the island of Jamaica, little information was available for mortality rates. Only one of the years was included in the database. This does not give any representation of the trend over the years. Furthermore, if there is only one year of statistics available, it is not clear whether or not this number is representative for the actual mortality rate of the country. When data on mortality were compared to the newly published NCDs country profiles by the WHO, this report shows that almost no mortality data on NCDs were reported on the Caribbean SIDS [54]. Both the results and the lack of reported NCD profiles imply that the vital registration system is not functioning properly. Moreover, the Report of the Caribbean Commission on Health and Development (2006) underlines that the vital registration of these islands is lacking. This report also states that there is not only an insufficient reporting of mortality rates and prevalence of diseases, but also that there is a chronic problem with the accurate certification of disease and deaths [2].

\section{Reflection of applied methodology}

This literature review was a multiple case study, where the structure of PC and health status of 16 Caribbean SIDS were reviewed using available literature between the years 1997 and 2014. Literature in English and Dutch was used for analyses. Even though 30 documents were used for analyses, more documents could have been used for this. Due to the geographical setting of the islands, which is close to Latin America, Spanish is often used as an official language. This could have affected the amount and the sort of information that was reviewed in this study. This could have affected results and there is the possibility that the gaps identified are not as great as suggested in the results of this study.

This study solely focuses on the structure of PC of the islands. As stated by Begun, Zimmerman, and Dooley [55], a health care system is a complex adaptive system and has a lot of different influences. A very significant dimension was not taken into account. The dimension of "Process of PC" could give more information on the provision of PC to the population and indirectly could have a relational trend on the populations' health. In addition, this dimension would have given a more comprehensive image of the performance of the whole PC system. Furthermore, several sources state that social determinants of health such as lifestyle and especially environmental factors (for these island it includes the hazards of hurricanes and volcanic activity) are a significant influence on the health status of the populations of these islands $[1,6,8]$. 
Previous studies have compared two to four small islands in the Caribbean region $[20,21,22,23]$. This review, where the structure of PC of Caribbean SIDS is evaluated and compared to one another, is the first of its kind. It can therefore be the starting point of a new line of research in this area. Health systems of Caribbean islands can highly benefit from comparative health systems research because they can learn from one another. Islands face similar issues and have similar populations and structures of health systems. Therefore, they have similar contextual factors. In this way these islands can innovate their health systems. Furthermore, comparative research can not only be used for the comparative analyses of solely Caribbean SIDS but also for other SIDS regions. SIDS in other regions can be compared with one another similarly to what was done in this study. In addition, regions of SIDS can be compared to one another when it comes to regional strategies.

In attempt to correct for missing data, the percentage of "the missings" was taken into account during calculations of the final results. Even though this was done, it might not have been the best method used to give the best possible representation of reality. Therefore, for future research on this topic, methods of correcting for missing data should be explored before scoring indicators.

\section{Conclusion and implications for the future}

When considering the results of this study it can be concluded that there is still little known on the functioning of PC systems in Caribbean SIDS. There is a need for elaborate research on: (1) How the functioning of the health system relates to the health status of the population of the islands; (2) What islands can learn from an analysis over time and what they can learn from cross-island analysis; and (3) Filling the gaps of knowledge which currently exist within this field of research. A more elaborate assessment, taking other vital parts into account such as other determinants of health and the provision of health care, can give a more realistic representation of how the PC systems of Caribbean SIDS are functioning. Nevertheless, this initial study has identified gaps and was the first of its kind to compare Caribbean SIDS on the basis of PC indicators. It can be used as a starting point for future research.

\section{Implications for the future}

In attempt to innovate and improve health systems of Caribbean SIDS, the following steps should be undertaken in order to do valuable comparison of these systems.

Closing knowledge gaps: A large amounts of gaps exist in currently available knowledge; future research should therefore focus on closing these gaps by collecting knowledge trough qualitative and quantitative means. For example, knowledge on the "governance of PC" is something that can be retrieved via interviews with governments of Caribbean
SIDS. After the retrieval of this information, it could be valuable to score this information comparable to how it was done in this study.

Creating "new" knowledge to get a complete representation of the current functioning of PC systems can be done by conducting a study with a similar design, but focussing on the dimension of "process of PC". New indicators for this study should be defined to assess currently available information comparable to the way it was done in this study. A next step in creating new knowledge would be to collect more in-depth information on the different dimensions on PC and the health status populations of the islands. This can be done by means of qualitative as well as quantitative research.

Cross-island comparisons is an essential step in innovating health systems; islands can learn significantly from other cases in similar context. Cross-island comparison can also initiate more regional-based strategies. Furthermore, if similar cross-island comparisons would be done in other SIDS regions, there is also the possibility of learning from the other SIDS regions.

\section{REFERENCES}

[1] United Nations General Assembly. Five-year review of the Mauritius Strategy for the further implementation of the programme of action for the sustainable development of small island developing states; 2010.

[2] PAHO and CARICOM. Report of the Caribbean Commission on Health and Development. Jamaica: Ian Randle Publishers; 2006. Available from: http://www.who.int/macrohealth/action/PAHO_ Report.pdf

[3] Phillips DR. Islands, health and development. Health Place. 1995;1(4):195-97.

[4] Easterly W, Kraay A. Small states, small problems? Income, growth, and volatility in small states. World Dev. 2000;28(11): 2013-27.

[5] Selwyn P. Smallness and Islandness. World Dev. 1980;8:945-51.

[6] SIDSnet. SIDSnet [Internet]; 2014; [cited 2014 February 8]. Available from: http://www.sidsnet.org

[7] PAHO. Health in the Americas 2007. Vol. II. Washington, DC; 2007. Available from: http://www2.paho.org/saludenlasamericas/ dmdocuments/health-americas-2007-vol-2.pdf

[8] PAHO. Health in the Americas 2012. 20th ed. Washington, DC; 2012. Available from: http://www.paho.org/saludenlasamericas/ index.php?option=com_content\&view=article \&id=9\&Itemid=14 \&lang=en

[9] Kruk ME, Porignon D, Rockers PC, Van Lerberghe W. The contribution of primary care to health and health systems in low- and middle-income countries: a critical review of major primary care initiatives. Soc Sci Med. 2010;70(6):904-11.

[10] Starfield B, Shi L, Macinko J. Contribution of primary care to health systems and health. Milbank Q. 2005;83(3):457-502.

[11] Kringos DS, Boerma WGW, Bourgueil Y, et al. The European primary care monitor: structure, process and outcome indicators. BMC Fam Pract. 2010;11(1):81.

[12] Maher D, Harries AD, Zachariah R, Enarson D. A global framework for action to improve the primary care response to chronic non-communicable diseases: a solution to a neglected problem. BMC Public Health. 2009;9(1):355.

[13] USSR. Declaration of Alma-Ata; 1978.

[14] Kringos D. The strength of primary care. Utrecht: NIVEL; 2012. 
[15] WHO. The World health report 2000. Health systems : improving performance. 2000. Available from: http://www.who.int/ whr/2000/en/

[16] Demas WG. The economics of development in small countries. Montreal: McGill University. Press; 1965.

[17] Mahabir D, Gulliford MC. Changing patterns of primary care for diabetes in Trinidad and Tobago over 10 years. Diabet Med. 2005;22(5):619-24.

[18] PAHO. Health system profile Trinidad \& Tobago. Washington, DC; 2008. Available from: http://www2.paho.org/hq/dmdocuments/ 2010/Health_System_Profile-Trinidad_Tobago_2009.pdf

[19] Pinto Pereira LM, Hinds A, Ali I, et al. Do current standards of primary care of diabetes meet with guideline recommendations in Trinidad, West Indies? Prim Care Diabetes. 2009;3(2):91-6.

[20] Rutten F, Lapré R, Antonius R, Dokoui S, Haqq E, Roberts R, Mills A. Financing of health care in four Caribbean territories: a comparison with reforms in Europe. Health Policy. 2002;62(1): 103-113.

[21] Mills A, Antonius R, Daniel J, Gray H, Haqq E, Rutten F. The distribution of health planning and management responsibilities between centre and periphery: historical patterns and reform trends in four Caribbean territories. Health Policy. 2002;62(1): 65-84.

[22] Walt G, Antonius R, Dokoui S, et al. The historical development of human resources policies in the health sector of four Caribbean territories: imitated or created? Health Policy. 2002; 62(1):85-101.

[23] Haqq E, Mills A. Health systems development in four Caribbean territories: introduction. Health Policy. 2002;62(1):55-63.

[24] Yisahak SF, Beagley J, Hambleton IR, Narayan KMV. Diabetes in North America and the Caribbean: an update. Diabetes Res Clin Pract. 2014;103(2):223-30.

[25] Government Grenada. Grenada national strategic plan for health (2007-2011); 2006. Available from: http://www2.paho.org/hq/ dmdocuments/2010/National_Health_Policies-Grenada-National_ Strategy_Plan_Health_2007-11.pdf

[26] Govindaraj R, Chellaraj G, Murray CJL. Health expenditures in Latin America and the Caribbean. Soc Sci Med. 1997;44(2): 157-69.

[27] PAHO. Health system profile saint Lucia. Washington, DC; 2010. Available from: http://www2.paho.org/hq/dmdocuments/2010/ Health_System_Profile-St_Lucia_2008.pdf

[28] PAHO. Health system profile St. Vincent and the Grenadines. Washington, DC; 2008. Available from: http://www2.paho.org/ hq/dmdocuments/2010/Health_System_Profile-Saint_Vincent 2008.pdf

[29] Ferguson TS, Tulloch-Reid MK, Cunningham-Myrie CA, Copeland S, Wilks RJ. Chronic disease in the Caribbean: strategies to respond to the Public Health Challenge in the region what can we learn from Jamaica's experience? Enfermedades Crónicas en el Caribe: Estrategias para Responder a los Retos de la Salud Pública en la Reg. 2011;60:876.

[30] Adams OP, Carter AO. Diabetes and hypertension guidelines and the primary health care practitioner in Barbados: knowledge, attitudes, practices and barriers-a focus group study. BMC Fam Pract. 2010;11(1):11-96.

[31] Government Antigua and Barbuda. National business plan for health Antigua and Barbuda 2008-2010; 2007. Available from: http://www2.paho.org/hq/dmdocuments/2010/National_Health_ Policies-Antigua_Barbuda-Business_Plan_Health_2008-10.pdf

[32] PAHO. Health systems profile St. Kitts and Nevis; 2008.

[33] PAHO. Health systems country profile Anguilla. Washington, DC; 2007. Available from: http://www2.paho.org/hq/dmdocuments/ 2010/Health-System-Profile-Anguilla-2007.pdf
[34] PAHO. Health systems country profile Antigua and Barbuda; 2010. Available from: http://www2.paho.org/hq/dmdocuments/ 2010/Health_System_Profile-Antigua_Barbuda_2008.pdf

[35] PAHO. Health systems country profile Barbados. Washington, DC; 2008. Available from: http://www2.paho.org/hq/dmdocuments/ 2010/Health-System-Profile-Barbados-2008.pdf

[36] PAHO. Health systems and services profile Dominica; 2002. Available from: http://www2.paho.org/hq/dmdocuments/2010/ Health_System_Profile-Dominica_2002.pdf

[37] PAHO. Health systems profile and services profile Grenada, Carriacou \& Petite Martinique; 2001. Available from: http:// www2.paho.org/hq/dmdocuments/2010/Health_System_ProfileGrenada_2001.pdf

[38] PAHO. Health system profile Monserrat. Washington, DC; 2008. Available from: http://www2.paho.org/hq/dmdocuments/2010/ Health_System_Profile-Monserrrat_2008.pdf

[39] PAHO. Health systems profile Puerto Rico. Washington, DC; 2007. Available from: http://www2.paho.org/hq/dmdocuments/ 2010/Health_System_Profile-Puerto_Rico_2007.pdf

[40] Hospedales CJ, Samuels TA, Cummings R, Gollop G, Greene E. Raising the priority of chronic noncommunicable diseases in the Caribbean. Rev. Panam. Salud Publica. 2011;30(4):393-400.

[41] PAHO. Health system profile St. Vincent and the Grenadines; 2008.

[42] PAHO. Health system and services profile of Jamaica; 2001. Available from: http://www2.paho.org/hq/dmdocuments/2010/ Health_System_Profile-Jamaica_2001.pdf

[43] PAHO. Health indicator database. Pan Am Heal Organ. 2009 [cited 2014 June 6]. Available from: www.paho.org.

[44] Asnani M, Brown P, O'Connor D, Lewis T, Win S, Reid MA. Clinical audit of the quality of care of hypertension in general practice. West Indian Med J. 2005;54(3):176-80.

[45] OECD. Health at a glance 2013: OECD Indicators; 2013. OECD Publishing. Available from: http://www.oecd.org/els/healthsystems/Health-at-a-Glance-2013.pdf

[46] Starfield B, Shi L, Macinko J. Contribution of primary care to health systems and health. The Milbank Quarterly. 2005;83(3): 457-502. doi:10.1111/j.1468-0009.2005.00409.x

[47] Starfield B. State of the art in research on equity in health. J Health Polit Policy Law. 2006;31(1):11-32.

[48] Filmer D, Hammer J, Pritchett LH. Health policies in poor countries: weak links in the chain; 1998. Available from: http://www-wds.worldbank.org/external/default/WDSContent Server/WDSP/IB/1998/01/01/000009265_3980312102556/ Rendered/PDF/multi0page.pdf

[49] Weiner JP, Starfield BH. Measurement of the primary care roles of office-based physicians. Am J Public Health. 1983;73(6): 666-71.

[50] Donaldson C, Gerard K. Economics of health care financing: the visible hand. 1st ed. London: Macmillan Press; 1993.

[51] Starfield B. Effectiveness of medical care: validating clinical wisdom. Baltimore: John Hopkins Univ. Press; 1985.

[52] Lofters AK. The "brain drain" of health care workers: causes, solutions and the example of Jamaica. Can. J. Public Hela. 2012; 5(103):e376-8

[53] PAHO. Human resources plans and primary health care: challenges for intersectoral and social participation. Washington, DC; 2011.

[54] WHO. Global status report on noncommunicable diseases 2014. Geneva; 2014. Available from: http://apps.who.int/iris/bitstream/ 10665/148114/1/9789241564854_eng.pdf?ua=1

[55] Begun JW, Zimmerman B, Dooley K. Health care organizations as complex adaptive systems; 2002. Available from: http://adapt knowledge.com/wp-content/uploads/rapidintake/PI_CL/media/ Begun_Zimmerman_Dooley.pdf 


\section{COMPETING INTERESTS}

The authors declare no competing interests.

\section{PUBLISHING NOTES}

(C) 2015 J.D. Kranenburg and D.R. Essink. This work has been published open access under Creative Commons Attribution License CC BY 4.0, which permits unrestricted use, distribution, and reproduction in any medium, provided the original work is properly cited. Conditions, terms of use and publishing policy can be found at www.scienceopen.com.
Please note that this article may not have been peer reviewed yet and is under continuous post-publication peer review. For the current reviewing status please click here or scan the QR code on the right.

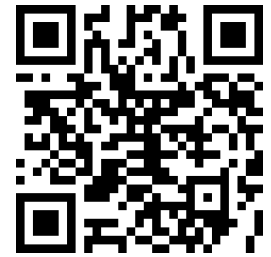

